\title{
INDIRECT HEATING SOURCE FOR TREATMENT OF MALIGNANT BRAIN TUMOURS ${ }^{\dagger}$
}

\author{
PHILIP C. THACKRAY and ZVI H. MEIKSIN \\ Department of Electrical Engineering, University of Pittsburgh, Pittsburgh, Pennsylvania 15261, USA \\ and \\ SIDNEY K. WOLFSON and ROBERT G. SELKER \\ Department of Neurosurgery, School of Medicine, University of Pittsburgh Laboratory of Surgical \\ Research, Montefiore Hospiial, Pittsburgh, Pennsylvania 15213, USA
}

(Received March 20, 1974)

\begin{abstract}
The design of an indirect heating source for the treatment of malignant brain tumors is presented. A high $Q$ resonant tank working at $25 \mathrm{kHz}$ generates a magnetic field of 16,000 ampere-turn/meter (peak) which is used to heat metallic implants by a combination of hysteresis and induced current heating. The resonant tank is used in a feedback loop of the power driver to maintain the driver at the resonant frequency, thus minimizing the power losses that inevitably occur in open loop systems due to reference oscillator drifts and/or varying load and tank conditions. Because of the high field strengths required and the relatively small power dissipation that occurs in the metallic implants, the overall system design differs substantially from standard induction heating applications.
\end{abstract}

\section{INTRODUCTION}

This paper discusses the development of a special purpose high magnetic field rf energy source for the treatment of malignant brain tumors. The biomedical background will be briefly reviewed to help clarify the special requirements and constraints of the system.

It is well established that reduced body temperature (hypothermia) lowers the metabolic rate in body tissues and organ systems. In cases where accessible tumors exist they have been experimentally treated by a method which involves hypothermia of the surrounding healthy tissues while the tumor is either held at normal body temperature (normothermia) or at an elevated temperature relative to the normal body temperature (hyperthermia)., ${ }^{1,2}$ If the malignant tissue is subjected to applications of a toxic chemotherapeutic agent (antimetabolite), the healthy tissue will be protected from the effects of the antimetabolite by its lower metabolic rate, the cancerous tissue being attacked in a normal way.

$\dagger$ Supported in part by ACS institutional grant No. 58M.
The application of this hypo-hyperthermic technique to the treatment of brain tumors is being explored in these laboratories (RGS and SKW). Since direct hyperthermia of a deep-seated tumor is difficult, a method involving the magnetic hysteresis and induced current heating by an external oscillating magnetic field of small stereotaxically implanted metal pieces is being studied. In conjunction with moderate total body hypothermia, this results in the establishment of a temperature gradient between the volume of brain in the immediate vicinity of the implants and the surrounding brain tissue. ${ }^{3}$ The magnitude of this gradient depends upon the mass of metal implanted and the intensity of the magnetic field. Present experiments involving live squirrel monkeys with small $(10 \mathrm{~mm} \times 1.6 \mathrm{~mm})$ low carbon steel implants have produced temperature gradients of $5^{\circ} \mathrm{C} / \mathrm{mm}$ in a reproducible fashion. ${ }^{3}$ A sharp fall-off in temperature $2-3 \mathrm{~mm}$ from the implanted metal has been noted, thereby facilitating control of the area to be heated.

Having created a sufficient temperature differential, indirect access by chemotherapeutic agents to the brain tumor can be achieved by perfusion into the brain's vascular system. As mentioned, the healthy 
tissues are protected from the antimetabolite by their lower metabolic rate. The addition of a technique of total circulatory arrest during hypothermia would increase the effectiveness of the above methods by allowing greater temperature differentials and reduced diluting effect of the toxic agent by normal blood flow in the brain. ${ }^{4}$

The previous work was carried out with a $5.5 \mathrm{~cm}$ $\left(2.75^{\prime \prime}\right)$ i.d. coil working at $37 \mathrm{kHz}$ with an input power of $1 \mathrm{~kW}$. The coil and driver circuits were provided by the Rawland-Borg Corporation of Chicago, Illinois, and designed primarily for hysteresis heating of particles of $\mathrm{Fe}_{2} \mathrm{O}_{3}, 0.02-0.1 \mu$ in size. ${ }^{3,5}$ Experiments with squirrel monkeys have determined that a field strength $\dagger$ of $16,000 \mathrm{At} / \mathrm{m}$ (peak) is sufficient to achieve the required temperature gradients in living brain tissue. However, implementation of the ideas discussed in the previous paragraph are awaiting the construction of a greater diameter field generator so that larger experimental animals, e.g. baboons, can be accommoaated. In the following sections the design and construction of a $0.15 \mathrm{~m}$ (6") i.d. system is discussed.

\section{DESIGN}

\subsection{General Considerations}

The power dissipation in the implanted metallic pieces will be only a few watts. However, the creation of a $16,000 \mathrm{At} / \mathrm{m}$ field in a $0.15 \mathrm{~m}$ diameter coil will require an input power on the order of $1 \mathrm{~kW}$ due to losses in the coil. As already noted, this situation is in sharp contrast to the standard induction heating application where a large percentage of the power is delivered to the work piece and losses in the work coil are almost negligible. Consequently, rf induction heaters are optimized for their ability to deliver power to the load and their open coil field strengths are much less than $16,000 \mathrm{At} / \mathrm{m}$. In the present case, loading is negligible and therefore load matching requirements are not applicable. The essence of the problem is the creation of very strong high frequency fields where no loading is assumed.

\subsection{The Resonant Tank}

The use of a resonant tank consisting of an inductor and a capacitor will be the most efficient circuit for

$\uparrow A$ current of 1 ampere flowing in a ring 1 meter in diameter creates a field of 1 ampere-turn/meter (abbreviation: $\mathrm{At} / \mathrm{m})$. this basically inefficient $(\sim 1 \%)$ system. In the limit as the tank series impedance goes to zero, there would be unlimited tank current and an infinite field with zero input power. This idealization serves to define the engineering approach: design a high $Q$ air core inductor-capacitor resonant tank to obtain a high field strength to input power ratio.

\subsubsection{Tank requirements The requirements for} the tank are:

a) Physical size - The coil diameter must be $0.15 \mathrm{~m}$ to accommodate the range of baboon head sizes, and must be sufficiently long so that a uniform field will be generated throughout a large enough volume. If the length is set to be $0.15 \mathrm{~m}$ also, a field will be set up which does not fall more than $10 \%$ below its axial value in a volume of about 0.3 liter near the center of the coil. The additional field uniformity which would be obtained by a Helmholtz coil arrangement would not justify the lower efficiency in this application.

b) To avoid any heating of normal tissue which would offset the hypothermia and yet maintain sufficient induced heating of the metallic particles, $25 \mathrm{kHz}$ was chosen as a compromise for these experiments. Furthermore, at this frequency a larger percentage of the heating effect will be due to magnetic domain motion (hysteresis heating) in the implant material. This is desirable because the amount of hysteresis heating is dependent only on the quantity of metal and not on the size and orientation of the implants geometry in the field as is the case with induced current heating. As the field frequencies approach the megaHertz range, induced current heating predominates in the metallic implants and normal tissue heating becomes significant.

c) Field strength - Preliminary work has shown that a field strength of $16,000 \mathrm{At} / \mathrm{m}$ is needed to create the required temperature gradient.

2.2.2 Tank components For power driver matching requirements discussed below, the parallel tank arrangement, rather than the series tank, was chosen. The tank is illustrated in Figure 1. Relationships between the tank parameters are given by the following equations:

$$
\begin{aligned}
& \text { Resonant frequency } f=\frac{1}{2 \pi(L C)^{1 / 2}} \\
& Q \text { factor } Q=\frac{2 \pi f L}{R_{s}}
\end{aligned}
$$




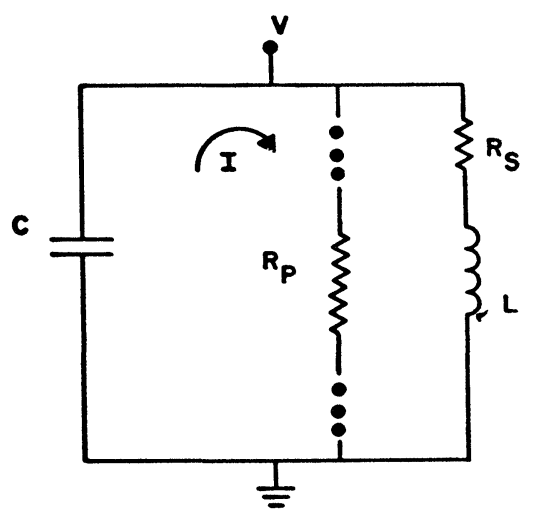

FIGURE 1 Basic resonant tank (equivalent parallel resistance shown).

$$
\begin{aligned}
& \text { Equivalent parallel resistance } \quad R_{p}=R_{s} Q^{2} \\
& \text { Necessary input power } \quad P_{\text {in }}=I^{2} R_{s} \\
& \text { Tank current } \quad I=\frac{V}{2 \pi f L}
\end{aligned}
$$

Central axial magnetic field

$$
H=\frac{I N}{d}\left(\frac{l}{\left(d^{2}+l^{2}\right)^{1 / 2}}\right) \mathrm{At} / \mathrm{m}
$$

where $L=$ inductance (henries), $C=$ capacitance (farads), $R_{s}=$ coil resistance (ohms), $l=$ coil length (meters), $d=$ coil diameter (meters) and $N=$ coil number of turns.

From Eq. (6) we find that for $l=d=0.15 \mathrm{~m}$ and $H=16,000 \mathrm{At} / \mathrm{m}$, the product $N I=3400 \mathrm{At}$ (peak). The choice of $N$ and $I$ should be dictated by the minimum input power requirement. The input power is given by Eq. (4) where the series resistance $R_{s}$ depends on the number of turns and coil configuration. If there existed a simple functional relationship between $R_{s}$ and $N$, an optimum value for $N$ could be derived analytically. Such a simple relationship, however, does not exist. If the coil turn spacing is large, then $R_{S}$ is a linear function of $N$. However, as $N$ increases, the coil spacing decreases to maintain a fixed coil length, and $R_{s}$ becomes a rapidly increasing function of $N$ whose exact form depends on the conductor geometry. This change is caused by the increased coupling between adjacent turns resulting in decreased utilization of conductor cross-section (skin effect).

The design optimization was done empirically at reduced currents as follows. It was decided to use $1 / 2$ " o.d. copper tubing for the solenoid to allow for water cooling. The tubing was flattened in a rolling unit to a $1 / 4^{\prime \prime}$ thickness and wound edgewise on a $0.15 \mathrm{~m}$ mandrel. A $25 \mathrm{kHz}$ current was applied to the solenoid and the field strength and input power were measured as a function of turn spacing while maintaining the length of the coil constant. A maximum value of the ratio of the field strength to input power was found to exist for a spacing of 0.87 turn per $\mathrm{cm}$. This resulted in a coil consisting of 13 turns with a length and diameter of $0.15 \mathrm{~m}$. The measured value of inductance was $18.5 \mu \mathrm{H}$. At $25 \mathrm{kHz}$, the series resistance was $25 \mathrm{~m} \Omega$, and the $Q$ factor was 105 . For a peak field strength of $16,000 \mathrm{At} / \mathrm{m}$ the peak coil current, from Eq. (6), is $260 \mathrm{~A}$, and from Eqs. (4) and (2) the maximum rms input power required is $900 \mathrm{~W}$.

To complete the tank, a capacitor must be chosen. From Eqs. (1) and (2) it is found that a $2.5 \mu \mathrm{F}$ capacitor rated at $190 \mathrm{~A} \mathrm{rms}, 500 \mathrm{~V} \mathrm{rms}$ with $Q$ factor $\gg 105$ is needed. This capacitor was made up of 30 parallel $0.085 \mu \mathrm{F}$ polystyrene units each rated at $10 \mathrm{~A} \mathrm{rms}, 1000 \mathrm{~V} \mathrm{rms}$ with a minimum $Q=10,000$ at $25 \mathrm{kHz}$. Thus, the circuit $Q$ is determined only by the coil. The parallel input impedance of the tank at resonance was measured to be $288 \Omega$ and from Eq. (5) it follows that the tank voltage will be $\pm 700 \mathrm{~V}$ peak for a field strength of $16,000 \mathrm{At} / \mathrm{m}$. By tapping into the resonant tank, the required drive voltage and input impedance can be reduced so that a solid state driver can be used.

The tapping was accomplished by placing a second capacitor $C_{2}$ in series with the original capacitor $C_{1}$, see Figure 2. The input voltage $V_{T}$ and the input impedance $R_{\text {in }}$ are related to the tank voltage and the equivalent parallel resistance $R_{p}$ by the following

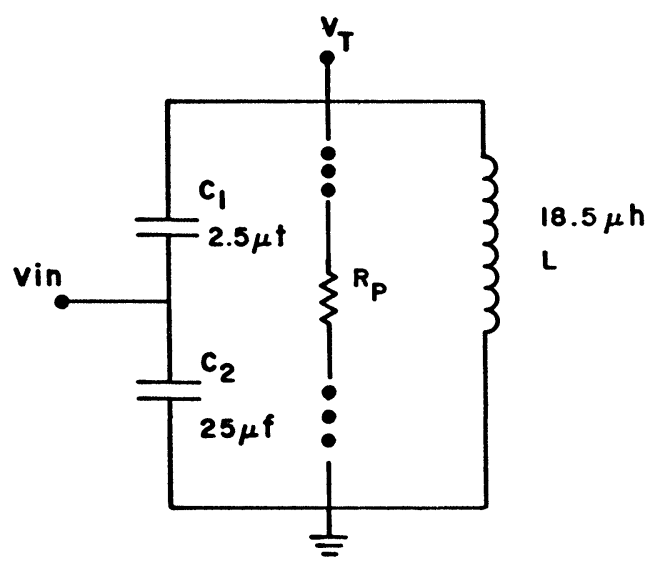

FIGURE 2 Tapped resonant tank. 
equations:

$$
\begin{aligned}
& V_{\text {in }}=\frac{Z c_{2}}{Z c_{1}+Z c_{2}}=\frac{C_{1}}{C_{2}+C_{1}} V_{T} \\
& \left.R_{\text {in }}=\frac{C_{1}}{C_{2}+C_{1}}\right)^{2} R_{p}
\end{aligned}
$$

where $V_{T}$ is the tank voltage, $Z c_{1}$ and $Z c_{2}$ are the impedances of capacitors $C_{1}$ and $C_{2}$, respectively and the other symbols were defined earlier. Letting $C_{1} /\left(C_{2}+C_{1}\right)=0.1$, then $C_{2} \approx 10 C_{1}=25 \mu \mathrm{F}$. The required drive voltage will be $\pm 70 \mathrm{~V}$ and the input impedance will be about $2.5 \Omega . C_{2}$ is composed of five parallel $5 \mu \mathrm{F}$ polystyrene units each rated at $50 \mathrm{~A} \mathrm{rms}$ and $300 \mathrm{~V}$ rms. The equivalent series resistance of the bank is $100 \mu \Omega$ at $25 \mathrm{kHz}$. If the inductor had been tapped, there would have been very few choices for the tap point and due to poor coupling additional losses would occur. The capacitor tap is virtually lossless. A picture of the completed tank appears as Figure 3.

\subsection{Power Driver}

The power driver must be capable of delivering $1 \mathrm{~kW}$ to the resonant tank. With a $\operatorname{tank} Q$ of 105 input requirements of the tank will change rapidly with deviations from the resonant frequency. For example, a $0.5 \%$ deviation will cut the magnitude of the input impedance by $1 / 2$. However, if the tank is used in a feedback loop of the power driver, changes in the resonant frequency due to varying load and/or tank conditions will be compensated. Such is not the case in standard induction heating devices where, because of extremely low $Q$, the load appears resistive over a large range of frequency. Consequently, these systems can be driven by reference oscillators with no feedback from the work coil itself.

\subsubsection{Driver design The input impedance at the} tap point of the resonant tank will be purely resistive only at the resonant frequency. If the power driver is a trans-conductance amplifier (i.e. characterized by the equation $I_{\text {out }}=g V_{\text {in }}$ where $I_{\text {out }}$ is the output current, $V_{\text {in }}$ is the input voltage, and $g$ is the transconductance of the amplifier), see Figure 4, then the output voltage when driving the resonant tank, will be in phase with the input voltage only at the resonant frequency. If the output voltage is fed back to the noninverting input via a zero phase shift scaling circuit then we have an oscillator whose frequency is the frequency of the tank. In Figure 4, resistors

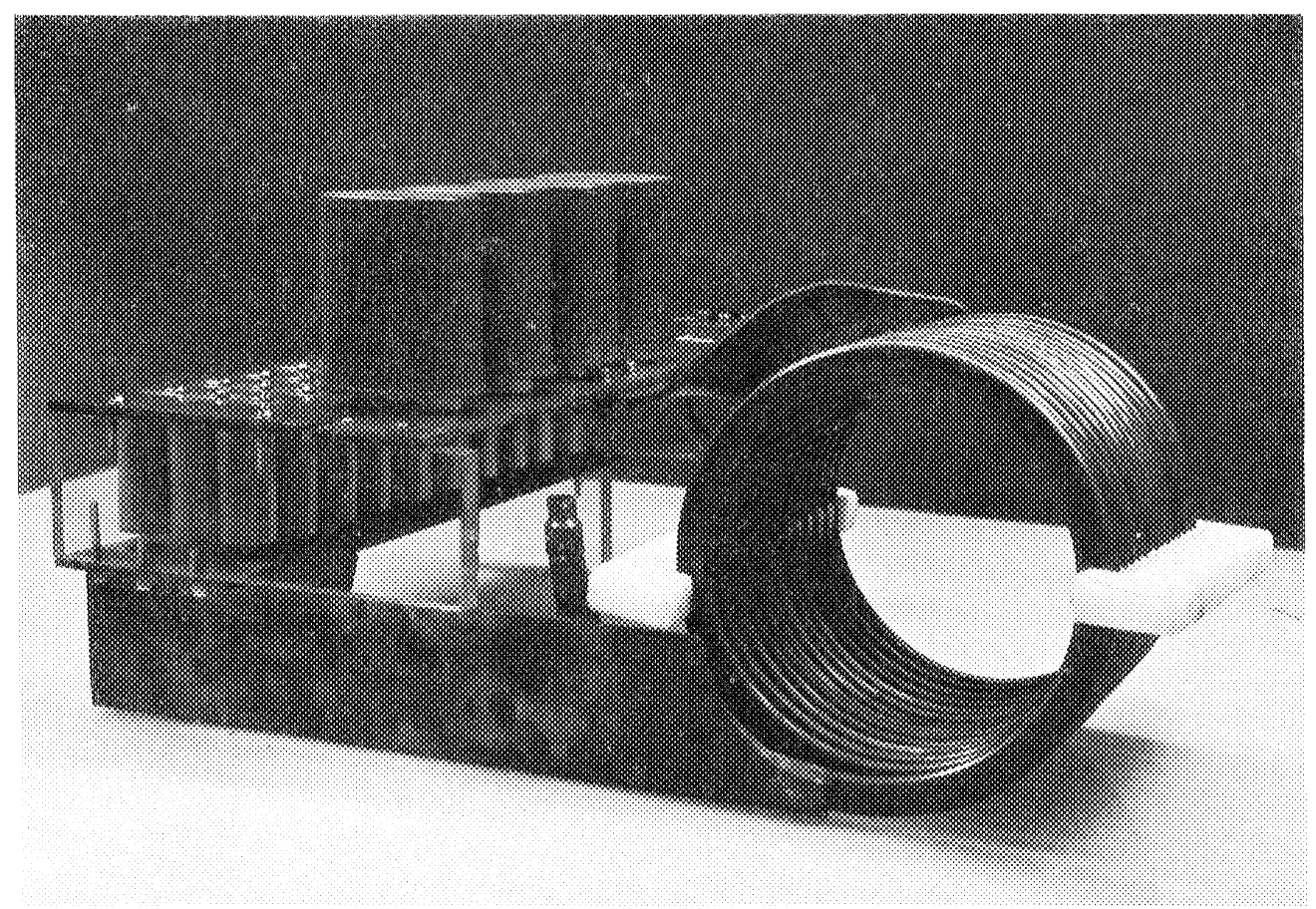

FIGURE 3 Resonant tank. 


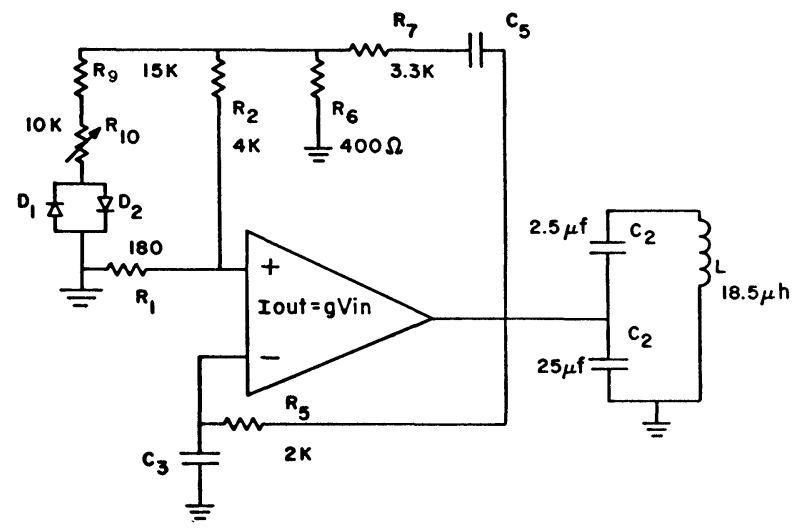

FIGURE 4 Power driver and resonant tank.

$R_{6}-R_{7}$ and $R_{2}-R_{1}$ are two voltage dividers which feed a fixed percentage of the output voltage back to the noninverting input. The resistive values are chosen so that a loop voltage gain slightly greater than unity is achieved. If the input resistance of the tank at resonance is $R=2.8 \Omega$, then the forward voltage gain is:

$$
\frac{V_{\text {out }}}{V_{\text {in }}}=g R=75 \Omega^{-1} \times 2.8 \Omega=210 .
$$

If a feedback attenuation of $1 / 200$ is chosen, then the total loop gain will be

$$
210 \times \frac{1}{200}=1.05 .
$$

This assures that oscillations will begin, and the output level will increase until the branch composed of $R_{9}, R_{10}, D_{1}$ and $D_{2}$ begins to shunt current away from divider $R_{2}-R_{1}$ thereby lowering the loop gain. The equivalent small signal resistance of the diodes is $26 \mathrm{mV} / I_{d}$, where $I_{d}$ is the diode current, so the resistance of this branch is a decreasing function of the voltage at the top of $R_{9}$. Thus, the shunting effect is voltage sensitive and variable resistor $R_{10}$ determines the voltage at which this shunting effect will be significant. A stable output is obtained and $R_{10}$ determines the output voltage swing.

Resistor $R_{5}$ provides $100 \%$ d.c. voltage feedback to maintain the d.c. component of the output at the ground level. For a.c., $C_{5}$ shunts this feedback to ground so that no overall negative feedback is used at the resonant frequency.

Figure 5 shows the details of the transconductance block along with the feedback loops just discussed. The amplifier $\mu 715$ provides voltage gain and establishes good inverting and noninverting inputs. A unity voltage gain current amplifier, LHOOO2, couples the $\mu 715$ to the input of the power predriver stage. Transistor $Q_{1}$ establishes the quiescent biasing conditions in the remaining stages and in conjunction with $C_{4}$ couples the input drive to the base of $Q_{2}$.

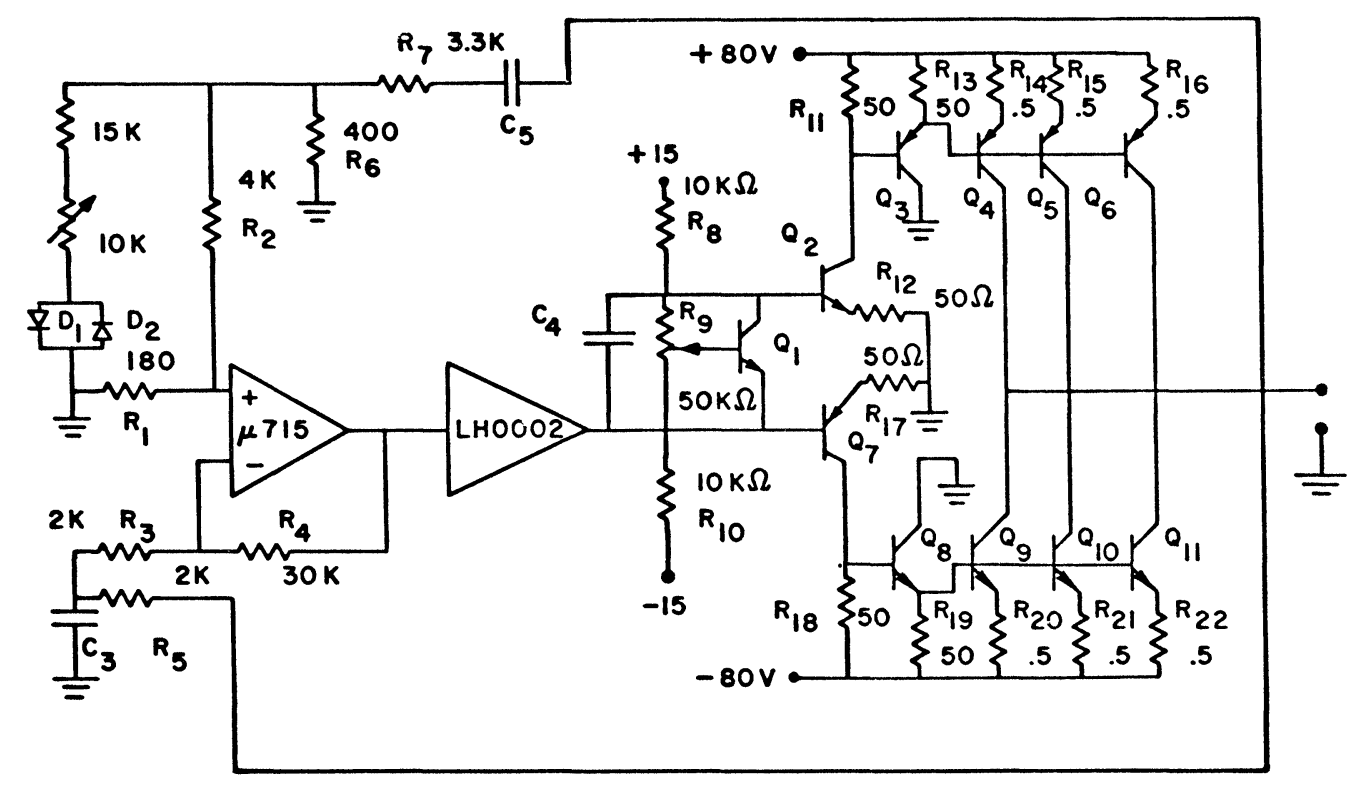

FIGURE 5 Power driver. 
Potentiometer $R$ is adjusted to set a $50 \mathrm{~mA}$ d.c. bias current in each output transistor. This eliminates crossover distortion and ensures that sufficient gain exists for the small noise voltages that are necessary to start oscillations.

Positive input signals are inverted and level shifted by $Q_{2}$. This stage has unity gain, a $2 \mathrm{k} \Omega$ input impedance, and a $50 \Omega$ output impedance. This voltage is used to drive the emitter follower $Q_{5}$ which supplies the necessary current to drive the paralleled bases of the output transistors $Q_{4}-Q_{6}$. The $0.5 \Omega$ resistors in the output transistor emitters establish the transconductance characteristic of the amplifier: the collector current in each output device is just the input voltage divided by the $0.5 \Omega$ emitter resistor. $Q_{7}$ through $Q_{11}$ perform a symmetric function on negative signals.

The amplifier must be sufficiently linear to minimize the power lost when harmonic distortion currents are shunted to the high $Q$ resonant tank. In this design no overall negative feedback is used, but sufficient $(<2 \%$ distortion) linearity is obtained by using large amounts of feedback at each stage. This avoids the stability problems associated with overall feedback and allows the use of relatively inexpensive silicon audio power transistors to obtain full power response at $25 \mathrm{kHz}$.

All of the power transistors $\left(Q_{2}-Q_{11}\right)$ in the driver are physically mounted on a water cooled copper plate. Water passages are located directly below the chip center in the TO3 package. With an amplifier designed to deliver $1 \mathrm{~kW}$, each of the six output devices will dissipate $100 \mathrm{~W}$ (although this maximum dissipation occurs at an output power less than $1 \mathrm{~kW}$ ). With this cooling arrangement, case temperatures never exceed $50^{\circ}$ at $100 \mathrm{~W} /$ device and the corresponding maximum junction temperature for these 200 watt devices is:

$$
0.875^{\circ} \mathrm{C} / \mathrm{W} \times 100 \mathrm{~W}+50^{\circ} \mathrm{C}=130^{\circ} \mathrm{C} \text {, }
$$

which leaves a safety margin of:

$$
\frac{200^{\circ} \mathrm{C}-130^{\circ} \mathrm{C}}{0.875^{\circ} \mathrm{C} / \mathrm{W}}=80 \mathrm{~W} / \text { device. }
$$

The total output into $2.5 \Omega$ is $\pm 28 \mathrm{~A}$ (peak) and \pm 70 $\mathrm{V}$ (peak) at $25 \mathrm{kHz}$.

In the three phase power supply (Figure 6) the three transformer primaries are delta connected. Each secondary winding is center tapped and uses a full

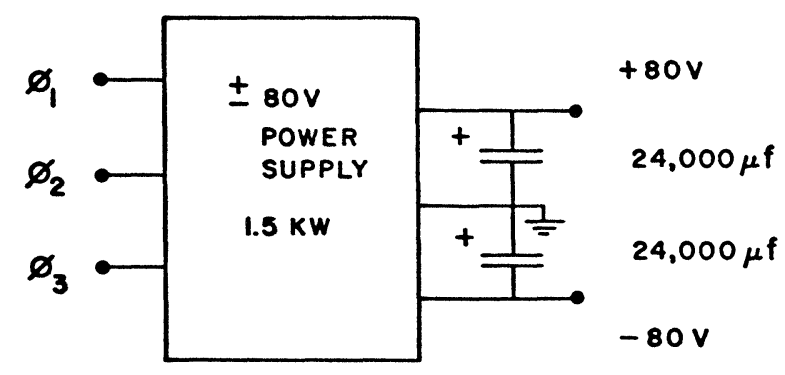

FIGURE 6 Power supply.

wave bridge. This results in a \pm d.c. supply with 360 $\mathrm{Hz}$ ripple on each supply. The $24,000 \mu \mathrm{F}$ filter capacitors are constructed from $4-6000 \mu \mathrm{F}$ units. The 30 A half-wave current pulse drawn at $25 \mathrm{kHz}$ from each supply cause a $1 \mathrm{~V}$ pp ripple. The $360 \mathrm{~Hz}$ ripple is $4 \mathrm{Vpp}$.

\section{DISCUSSION}

The original $5.5 \mathrm{~cm}$ diameter system requires an input power of $1 \mathrm{~kW}$ to produce a field of $16,000 \mathrm{At} / \mathrm{m}$ in a cross-sectional area of $24 \mathrm{~cm}^{2}$. The system just presented uses the same input power to produce a similar field over a crossectional area of $178 \mathrm{~cm}^{2}$. This represents an increase in flux production efficiency of 7.44 times. Greater electrical efficiency could have been obtained by using super conducting coils, but the cost efficiency of such an arrangement would be very much less and the overall system complexity and size would be greatly increased.

\section{REFERENCES}

1. V. P. Popovic, and R. Masironi, "Effect of general hypothermia on normothermic tumors." Am. J. Physiol, 211. 462 (1966).

2. V. P. Popovic, and R. Masironi, "Enhancement of 5 flurouracil action on normothermic tumors by generalised hypothermia," Cancer Res., 26, 2353 (1966).

3. R. G. Selker, S. K. Wolfson, Jr., R. Medal, and M. Miller, "Creation of a chemothermal gradient in treatment of brain tumors," Surgical Forum, 24, 461-463 (1973).

4. S. K. Wolfson, and R. G. Selker, "Carotid perfusion hypothermia for brain surgery using cardiac arrest without bypass," J. Surg. Res. 14, $449-458$ (1973).

5. R. Medal, et al., "Controlled radio frequency generator for production of localized heat in intact animal," Arch. Surg., 79, 427-431 (1959). 

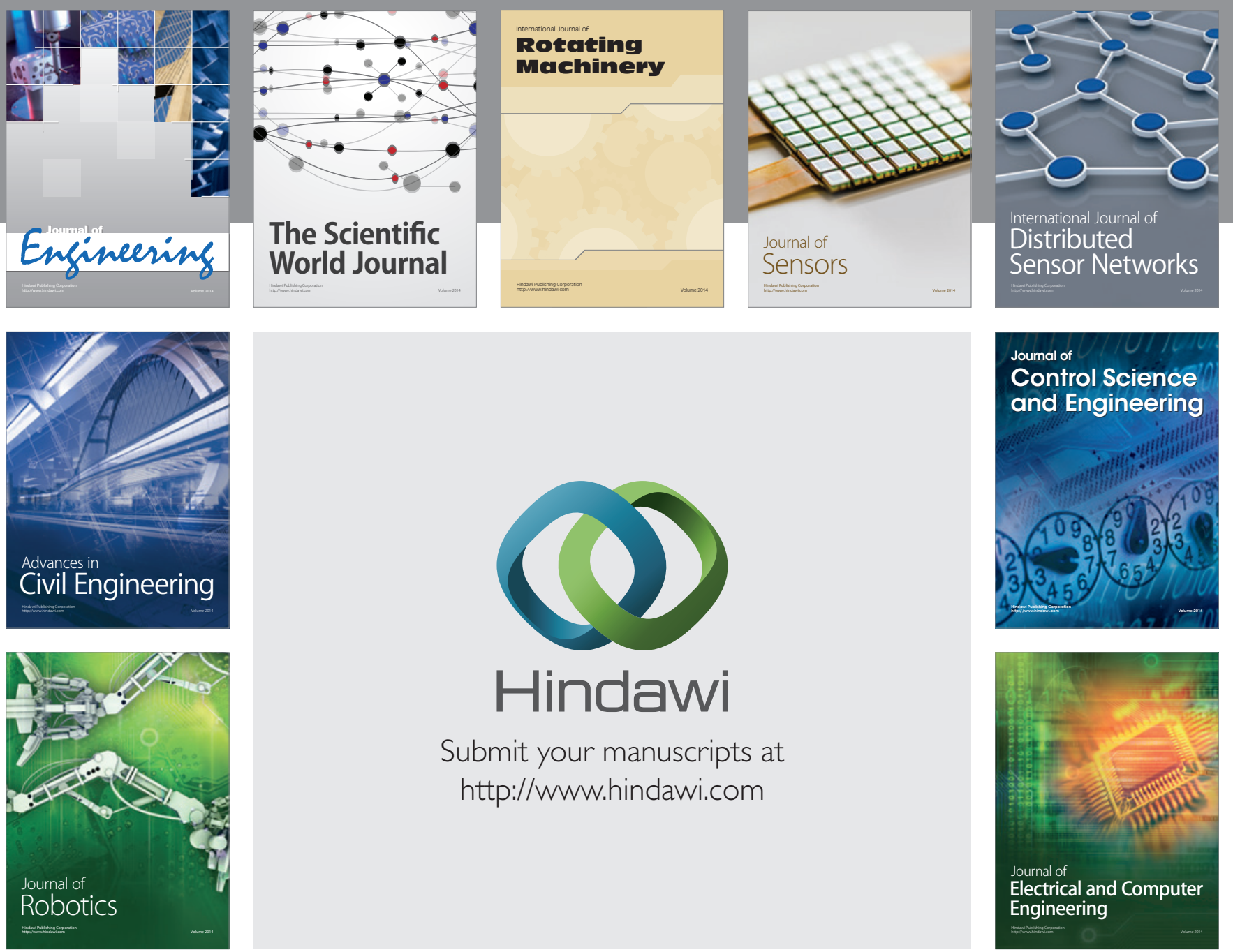

Submit your manuscripts at

http://www.hindawi.com
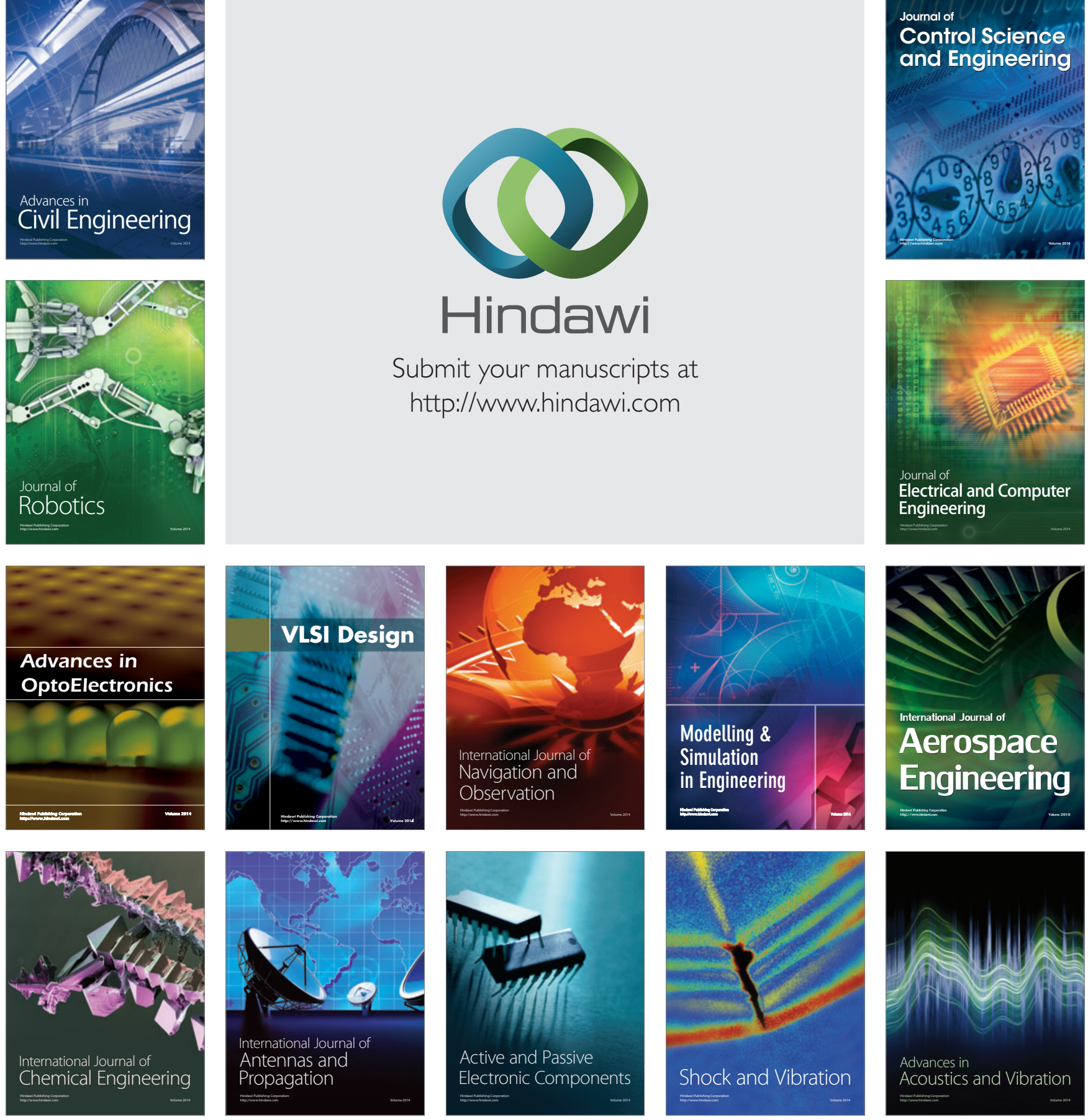